\title{
Inhibiting shale hydration and dispersion with amine-terminated polyamidoamine dendrimers
}

Hanyi Zhong, Zhengsong Qiu*, Daoming Zhang, Zhichuan Tang, Weian Huang, Weiji Wang School of Petroleum Engineering, China University of Petroleum, Qingdao 266580, China Correspondence*: Zhengsong Qiu, School of Petroleum Engineering, China University of Petroleum, Qingdao, 266580, China. Tel: 0086-532-86983576, Fax: 0086-532-86981936, Email: zhong3h3c@sina.com

\begin{abstract}
Dendrimers have been paid increasing attention in the area of drilling fluid recently due to their unique structure and properties. The inhibitive properties of amine terminated polyamidoamine (PAMAM) dendrimers ranging from G0 to G5 were evaluated by relative inhibition rate, shale cuttings hot-rolling dispersion test and particle size distribution measurement respectively. Meanwhile the inhibitive capacity of the polymers under various $\mathrm{pH}$ value conditions was studied. The interaction between sodium bentonite and PAMAM dendrimers was characterized by zeta potential measurement and X-ray diffraction (XRD). The results indicated that, G0 and G5 are superior to polyether diamine, while G1, G2, G3 and G4 perform better than $\mathrm{KCl}$. PAMAM dendrimers from G0 to G5 can decrease the zeta potential of clay particles from $-39 \mathrm{mV}$ to about $-22.6 \mathrm{mV}$ at natural $\mathrm{pH}$ values and reverse the charge when the $\mathrm{pH}$ value is adjusted to 9 . When intercalated into the clay interlayer in aqueous solution, the candidate PAMAM dendrimers can form monolayer arrangement at lower concentrations and reduce the interlayer spacing of hydrated clay from $1.95 \mathrm{~nm}$ to $1.38-1.63 \mathrm{~nm}$, which is the direct evidence of inhibiting shale hydration. With the increase of
\end{abstract}


concentration, mixed phase and bilayer orientation are formed in the interlayer. The multi-terminal amine groups of dendrimers can effectively bind the adjacent layers together with electrostatic attraction and hydrogen bonding, and expel the water molecules out of the interlayer, contributing to the suppression of clay swelling and dispersion. The $\mathrm{pH}$ value reduction of aqueous solution improves the protonation of terminal-amine group, which can intensify the interaction between the polymers and clay, inducing the decrease of hydrated interlayer spacing and the zeta potential of clay particles, thus enhancing the inhibitive properties.

Keywords: polyamidoamine; dendrimers; shale hydration; interlayer spacing; protonation

\section{Introduction}

It is always a worldwide challenge for well drilling in shale formations due to the wellbore instability problems induced by the interaction between shale and aqueous filtration including tight hole, sloughing, washout, caving and so on (Al-arfaj et al., 2014; Stelger and Leung, 1998). Oil-based drilling fluids are the first choice for most shale formations because of the outstanding shale stability, however, the drawback of high cost and stringent environmental legislation make them a much less attractive alternative than before (He et al., 2014; Stamatakis et al., 1995; Suter et al., 2011). Consequently, much research has been transferred to improve the inhibitive properties of water-based drilling fluids with the eventual goal of replacing oil-based drilling fluids, which is also a hallmark of high performance water-based drilling fluid (Galindo et al., 2015).

Based on the understandings of shale hydration mechanisms and the physical-chemical interactions between shale and drilling fluid, lots of work has been carried out to evaluate and 
seek solutions to mitigate and control the reactive shale formations during the past decades (Van Oort et al., 1994; Van Oort, 1997). Numerous chemicals including inorganic salts, formates, organic amine compounds, polymers, silicates and polyglycerols have been used with different mechanisms such as hydration inhibition, reduction of pore pressure transmission, or cuttings encapsulation (Galindo et al., 2015; Patel et al, 2007; Reid et al., 1995; Van Oort, 2003; Xuan et al., 2013; Zhang et al., 2001). Based on these chemical inhibitors, several inhibitive water-based drilling fluids have been established and utilized in the field (Donham and Young, 2009; Patel and Gomez, 2013; Stamatakis et al., 1995; Young and Ramses, 2006). Nevertheless, it is not completely successful for these fluids to inhibit the hydration and dispersion of reactive shales with various performance limitations (Patel et al., 2002). Therefore, developing new highly inhibitive and environmentally friendly shale inhibitors is still an ongoing endeavor and research hotspot.

Dendrimers have been paid extensive attention since the first synthesis because of their unique characteristics such as highly ordered structure, narrow size distribution, and uniform dense terminal functional groups, which render the polymers as ideal candidates in a wide range of applications (Abdel Rehim et al., 2010; Mo et al., 2008). Recent studies have shown that dendrimers have potential application in the area of oilfield chemistry (Amanullah, 2013; Kaiser, 2013; Lai et al., 2013; Li et al., 2012; Rivers et al., 2011; Stanciu et al., 2015). As far as drilling fluid is concerned, Amanullah (2013) illustrated a promising potential of developing high performance drilling fluid in future challenging conditions with the use of dendrimers. Miller (2011) applied a patent that poly(propyleneimine) dendrimers and polyamine twin dendrimers can be used as shale hydration inhibition agent and high 
temperature resistant to $500^{\circ} \mathrm{F}$. Teixeira et al. (2014) synthesized hyperbranched polyglycerols and evaluated their inhibitive performance. The results showed that the polymer has a great potential to be environmentally friendly inhibitor in water-based drilling fluid. In a recent study, elaborated dendritic polymers were designed and synthesized to reduce the fluid loss with temperature resistance of $260{ }^{\circ} \mathrm{C}$ in water based drilling fluid (Zhang et al., 2015).

PAMAM dendrimers, first synthesized by the Tomalia et al. (1985), are one of the most widely used dendrimers (Gillies et al., 2005). According to the molecular design rule of the clay swelling inhibitor (Suter et al., 2011), the unique characteristics including high density of terminal amine group and ellipsoidal or spheroidal structure of PAMAM dendrimers make them suitable for shale inhibition. The feasibility of PAMAM dendrimers as shale stabilizers has been investigated in our previous work (Zhong et al., 2015). The purpose of this paper is to further study the effect of PAMAM dendrimers on shale hydration and dispersion suppression under different $\mathrm{pH}$ values, and establish a relationship between the molecular structure of PAMAM dendrimers and stabilization of reactive shales.

\section{Experimental}

\subsection{Materials}

Different generations (from G0 to G5) of amine terminated polyamidoamine (PAMAM) dendrimers with ethylene diamine as initial core, were purchased from Sigma-Aldrich (Fig. 1). Polyether diamine (PEA) with molecular weight of 230 was provided by BASF Chemical Co. Potassium chloride was purchased from Sinopharm Chemical Reagent Co., Ltd, China with analytical purity. Sodium bentonite was provided by Boyou bentonite Group Co., Ltd, China, and the detailed mineralogical composition was presented in mass percentage as 
follows: montmorillonite, $57.6 \%$, illite, $1.2 \%$, kaolinite, $0.6 \%$, chlorite, $0.6 \%$, quartz, $32 \%$, potassium feldspar, 8\%. The cation exchange capacity (CEC) was determined to be 74 mmol/g. Drilling fluid bentonite was obtained from Weifang Huawei Bentonite Group Co., Ltd, China, following the American Petroleum Institute (API) standard. All of the chemicals were used as received without further purification.

The shale cuttings used for shale dispersion tests were provided by Zhundong Drilling Company from Well Yueman 6 of Tahe oilfield. The detailed mineralogical composition of the shale cuttings was identified using X-ray diffraction (XRD) and shown as follows, quartz, $41 \%$, K-feldspar, $5 \%$, plagioclase, $15 \%$, calcite, $17 \%$, iron dolomite, $4 \%$, kaolinite, $1 \%$, chlorite, $1 \%$, illite, $7 \%$, interlayered illite-smectite, $9 \%$.

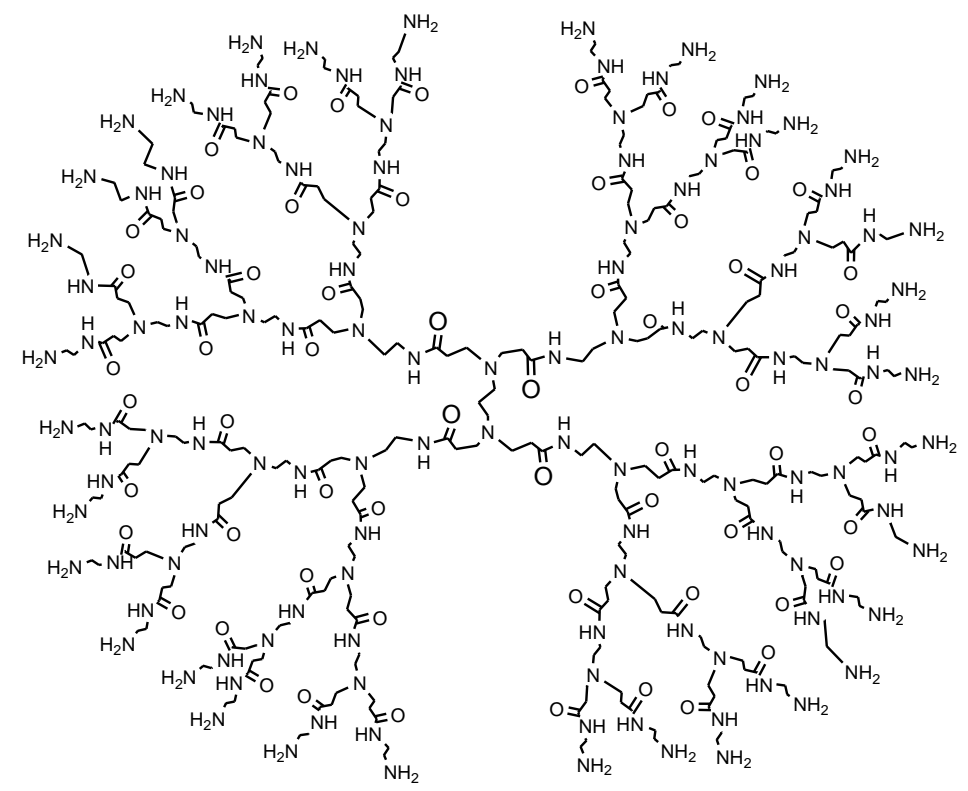

Fig. 1 Structures of the PAMAM dendrimers to be studied (G3).

\subsection{Methods}

\subsubsection{Relative inhibition rate}

Inhibitor solution containing $350 \mathrm{~mL}$ fresh water and $3.5 \mathrm{~g}$ inhibitor sample was prepared.

Drilling fluid bentonite ( $35 \mathrm{~g}$ ) was incorporated into the solution and stirred at 10,000 rpm for 
20 minutes. Then the dispersion was hot-rolled at $120^{\circ} \mathrm{C}$ for 16 hours. After cooling to ambient temperature, the rheological properties of the dispersion were determined by ZNN-D6 rotational viscometer (Qingdao Haitongda Special Instrument Co., Ltd). The relative inhibition rate was calculated according to the following equation.

$$
\mathrm{R}=\frac{\phi 100-\phi 100^{\prime}}{\phi 100} \times 100 \%
$$

where, $\mathrm{R}$ is relative inhibition rate, $\$ 100$ and $\Phi 100$ ' are 100 dial reading of control sample and inhibitor sample respectively.

\subsubsection{Shale cuttings hot-rolling dispersion test}

This test was designed to evaluate the dispersion of shale cuttings after exposing to a formulated fluid in a rolling oven cell at setting temperatures. In this test, mass of $40 \mathrm{~g}$ shale cuttings from Well Yueman-6 and $280 \mathrm{~mL}$ aqueous solution containing 2w/v\% inhibitor samples were added to the roller oven cell. After hot rolling at $77^{\circ} \mathrm{C}$ for 16 hours, the fluid and shale were cooled to ambient temperature and screened with 40 mesh sieve. The remaining shale cuttings were washed and recovered. After dried at $105^{\circ} \mathrm{C}$ for 4 hours, the recovered shale cuttings were weighed and the percentage recovery of the shale cuttings was determined.

\subsubsection{Particle size distribution measurement}

Particle size distribution measurement can be used to assess the inhibition ability of shale inhibitors (Liu et al., 2004). Mass of $16 \mathrm{~g}$ sodium bentonite was added into $400 \mathrm{~mL}$ deionized water and stirred vigorously for 1 hour. Then the dispersion was incubated for at least 24 hours. After that, $4 \mathrm{~g}$ shale inhibitors were added into the dispersions and stirred for 24 hours. The particle size distribution of the dispersion was measured by Bettersize 2000 particle size 
analyzer (Bettersize instruments Ltd., China).

\subsubsection{Zeta potential measurement}

Zeta potential was measured with a Zetasizer Nano ZS90 (Malvern instrument, United Kingdom). Inhibitor solution containing $1 \mathrm{~g}$ inhibitor and $97 \mathrm{~mL}$ deionized water was prepared. Then $3 \mathrm{~g}$ Boyou sodium bentonite was added into the solution and vigorously stirred for 24 hours. Before the measurement, the dispersion was diluted to make the particles visible under the microscope. The zeta potential of each sample was tested three times and their average was taken as the final result. After adjusting the $\mathrm{pH}$ value to about 9 with hydrochloric acid, the $\mathrm{pH}$ value of the dispersion was measured with $\mathrm{pH}$ meter and the related zeta potential was derived.

\subsubsection{Measurement of interlayer spacing with X-ray diffraction (XRD)}

Firstly, sodium bentonite dispersion containing $7 \mathrm{~g}$ sodium bentonite and $350 \mathrm{~mL}$ deionized water was prepared first. Then PAMAM dendrimers were added into the dispersion with the content of $0.35,0.70,1.75,2.80$ and $7.00 \mathrm{~g}$ respectively. The dispersion was stirred for another 24 hours to establish adsorption equilibrium. The $\mathrm{pH}$ value of the dispersion was adjusted by $0.1 \mathrm{~mol} / \mathrm{L}$ hydrochloric acid. Then the mixture was centrifuged at $8000 \mathrm{r} / \mathrm{min}$ for 20 min and washed three times to remove the un-adsorbed polymers. After centrifugation, the sedimentation was collected. One part of the sample was tested by X-ray diffraction directly to obtain the interlayer spacing, while the other part of the precipitation was dried at $105{ }^{\circ} \mathrm{C}$ and ground to fine powders. XRD patterns were recorded using an X'pert PRO MPD diffractometer with $\mathrm{CuKa}$ radiation operating at $45 \mathrm{kV}$ and $40 \mathrm{~mA}$. The interlayer spacing was analyzed by using Bragg's equation. The value for $\mathrm{n}=1$ was calculated from $2 d \sin \theta=n \lambda$. 


\section{Results and discussion}

In this section, the inhibitive properties of PAMAM dendrimers of different generations were evaluated at different $\mathrm{pH}$ values firstly. Then the inhibitive mechanism of PAMAM dendrimers was analyzed by zeta potential measurement and XRD. Finally a plausible model was proposed to illustrate the interaction between PAMAM dendrimers and clay.

\subsection{Inhibitive properties evaluation}

In order to compare the inhibitive properties between candidate PAMAM dendrimers and PEA and potassium chloride, typical inhibitive evaluation experiments including relative inhibitive rate measurement and shale cuttings hot-rolling dispersion test were performed. Meanwhile the interaction between shale inhibitors and clay particles will influence the colloidal properties of clay particles, therefore, particle size distribution measurement was also carried out to probe the inhibition of PAMAM dendrimers.

\subsubsection{Relative inhibitive rate}

The effect of different inhibitors on yielding tendency of sodium bentonite was investigated by rheological tests. In fresh water system, clay particles will imbibe water rapidly in the process of surface hydration and osmotic hydration. After thorough hydration, even individual lamellar layers will form dimensional networks in the system, resulting in an increase of the viscosity of the dispersion. On the contrary, the system incorporating various inhibitors exhibited a lower 100 dialing readings, indicating a lower rheological profile compared to the control sample, corresponding to a higher relative inhibition rate which can be identified by equation 1. As shown in Fig. 2, the relative inhibition rate of PAMAM dendrimers was higher than that of potassium chloride, approaching to that of PEA, 
demonstrating that PAMAM dendrimers showed superior inhibitive performance to potassium chloride.

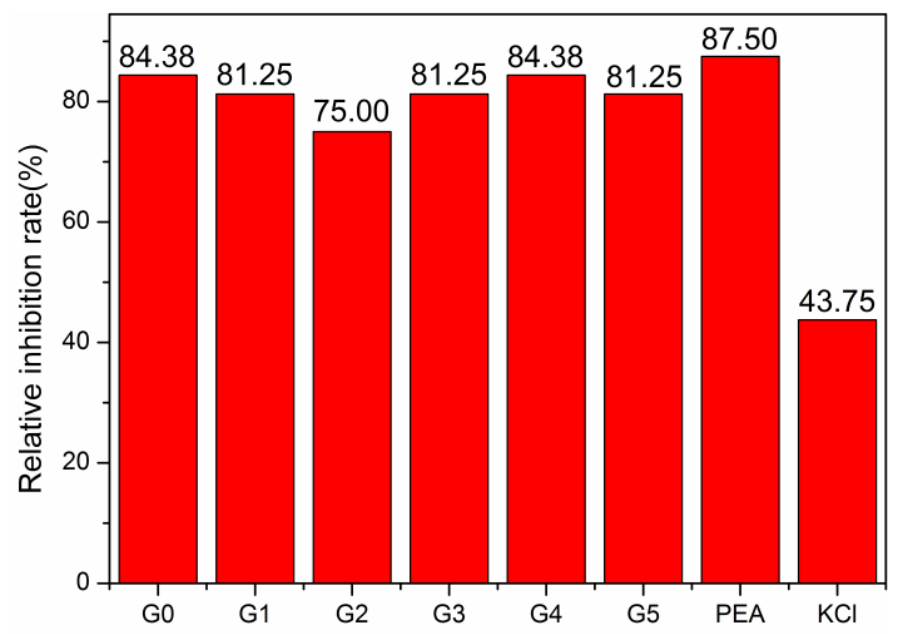

Fig. 2. Relative inhibition rate of various inhibitor systems.

\subsubsection{Shale cuttings hot-rolling dispersion test}

In order to investigate the effect of $\mathrm{pH}$ value on the inhibitive performance of PAMAM dendrimers, shale cuttings hot-rolling dispersion test and particle size distribution test were carried out under various $\mathrm{pH}$ values. As shown in Fig. 3, in comparison to the control sample, the shale cuttings recovery was improved greatly for PAMAM dendrimers of various generations, PEA and $\mathrm{KCl}$. High recovery is an indication of low dispersion of shale cuttings and highly effective inhibition. When the $\mathrm{pH}$ value of testing solution was 11 , the shale cuttings recovery of the candidate fluids followed the sequence of G5>G0> $\mathrm{PEA}>\mathrm{G} 1>\mathrm{G} 2>\mathrm{G} 3>\mathrm{KCl}$, demonstrating that $\mathrm{G} 5$ could be used as an efficient shale dispersion suppressant. When the $\mathrm{pH}$ value of the aqueous solution was adjusted to 9 , both the shale cuttings recovery of PAMAM dendrimers and PEA further increased obviously. However, G5 still exhibited the best inhibitive performance. For $\mathrm{KCl}$, the shale cuttings recovery was less influenced by the $\mathrm{pH}$ value. 


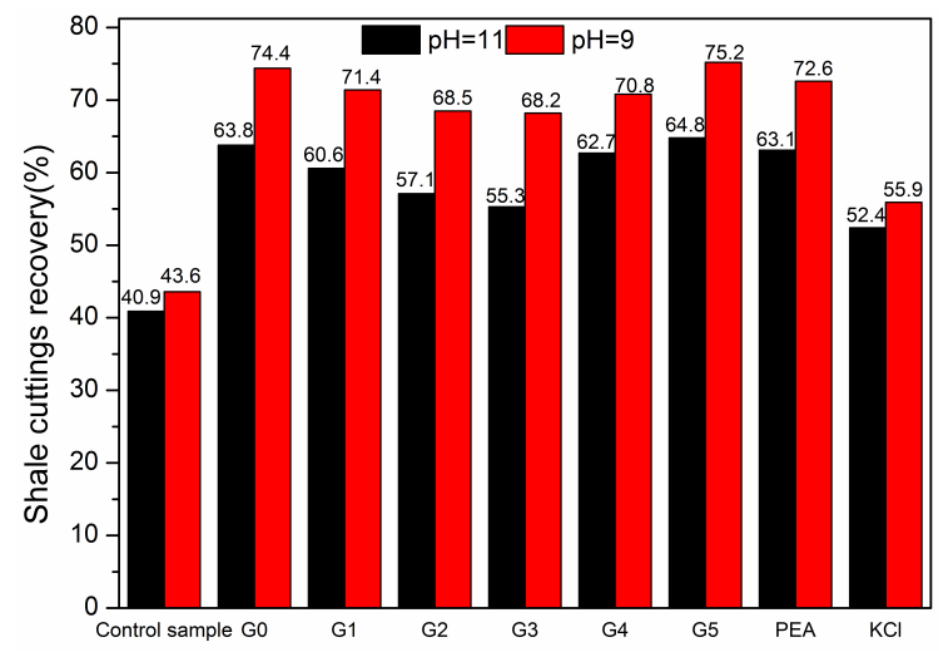

Fig. 3. Shale cuttings recoveries of different inhibitors at $\mathrm{pH}$ value of 11 and 9 respectively.

\subsubsection{Particle size distribution measurement}

Clay particles, mainly composed by montmorillonite, would disperse into fine particles and even single unit layers after thorough hydration. However, when shale inhibitors of cationic type are incorporated, the particle size would be obviously changed because of the interaction between the shale inhibitors and clay particles. The increase of particle size of the composites could be correlated to the occurrence of agglomeration. The effect of PAMAM dendrimers, $\mathrm{PEA}$ and $\mathrm{KCl}$ on the particle size of clay particles at natural $\mathrm{pH}$ value and 9 were determined and shown in Fig. 4 and Fig. 5, respectively. It could be obviously seen that, when the pH value of the dispersion was not adjusted, the control sample contained a large amount of small particles and a small part of great particles. The addition of inhibitors shifted the distribution curves to the right, corresponding to the increase of particle size. However, potassium chloride didn't have apparent effect on the particle size of clay. The distribution curves changed relatively little. When the $\mathrm{pH}$ value was adjusted to 9, the particle distribution curves shifted to even more right, demonstrating greater particles formed, namely, the inhibitive properties were improved with the decrease of aqueous $\mathrm{pH}$ value. As shown in 
Table 1, when the $\mathrm{pH}$ value of the dispersion was adjusted to 9 , the value of median size increased and specific surface area decreased for PAMAM dendrimers and PEA.

There are a number of amine groups on the outer surface of PAMAM dendrimers, which can be adsorbed onto the negative clay surface with multi-sites. This multi-adsorption can lead to the increase of particle size with two modes. On one hand, the positively charged PAMAM dendrimers neutralize the negative sites of clay surface and decrease the repulsion between clay particles. On the other hand, PAMAM dendrimers with numerous amine groups can be anchored on adjacent clay particles and bind the particles together. Thus the particles easily flocculate and become larger. When the $\mathrm{pH}$ value is reduced, the protonation of amine groups of PAMAM dendrimers intensifies this behavior, reflecting a further increase of particle size. Because there are only two amine groups at the terminal for PEA, it can't change the particle size as effectively as PAMAM dendrimers. Potassium ions just exchange with the hydrated sodium cations and have little effect on particle size.

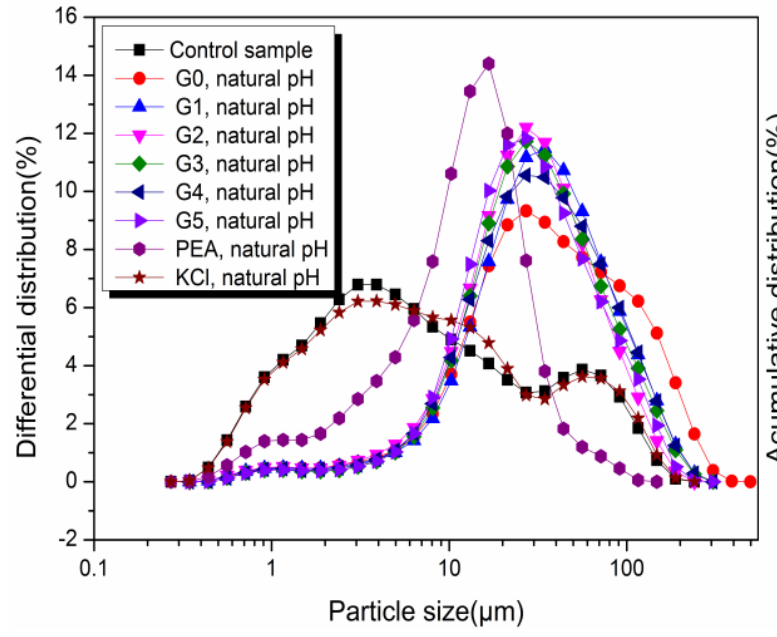

(a)

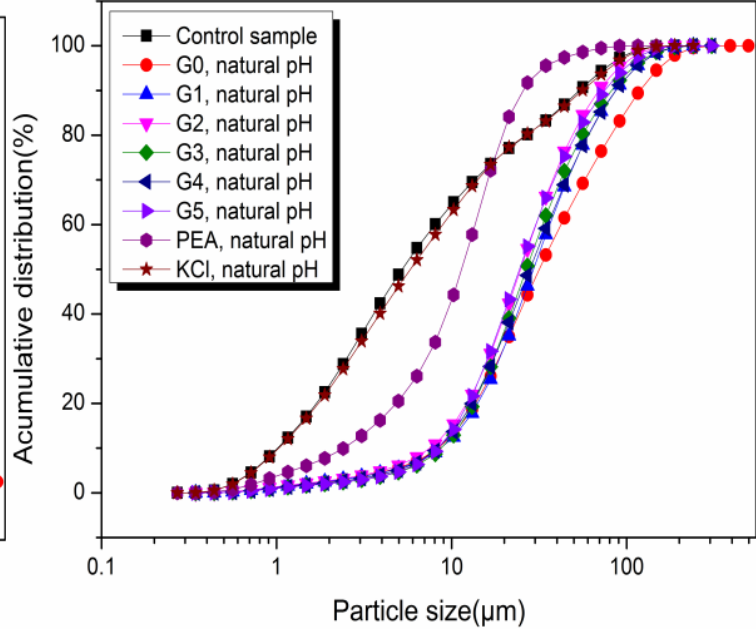

(b)

Fig. 4. Particle size distribution of different inhibitor systems at natural $\mathrm{pH}$ value. 


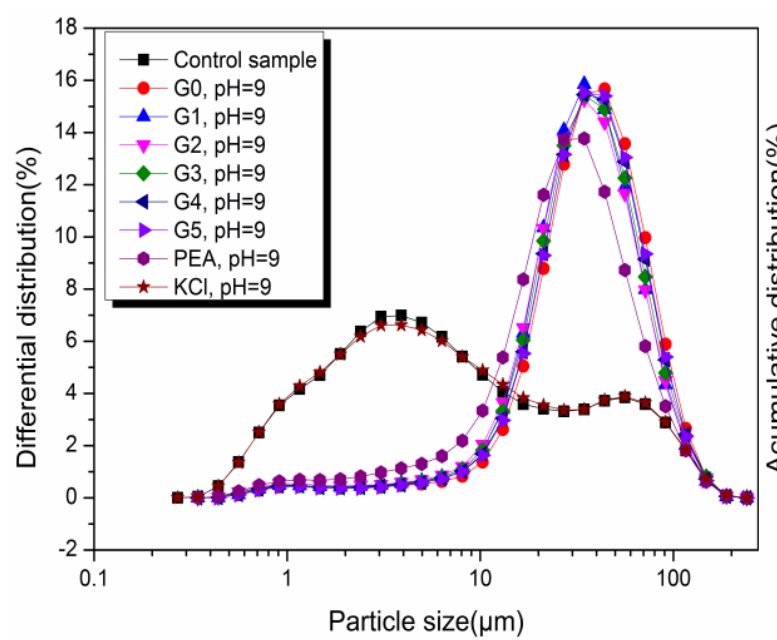

(a)

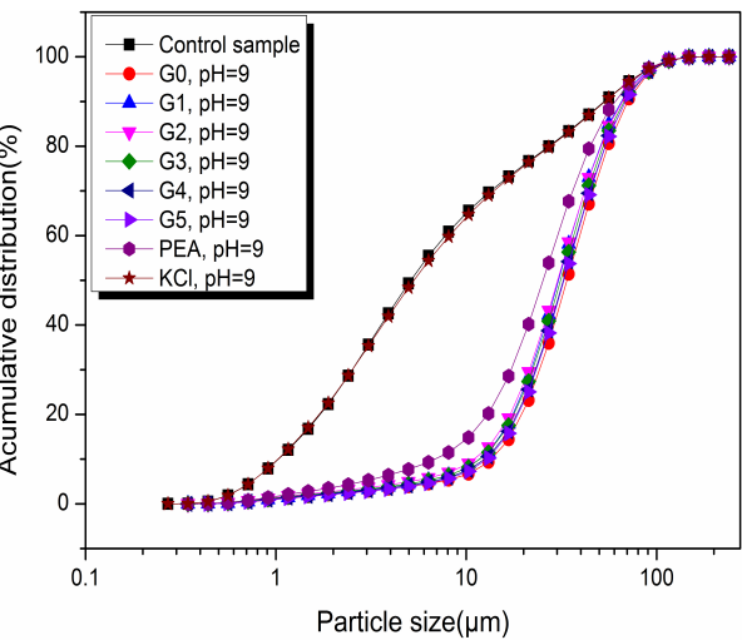

(b)

Fig. 5. Particle size distribution of different inhibitor systems at $\mathrm{pH}$ value of 9 .

Table 1 Particle size distribution of different inhibitor systems.

\begin{tabular}{ccccc}
\hline \multirow{2}{*}{ Parameter } & \multicolumn{2}{c}{$\mathrm{D} 50(\mu \mathrm{m})$} & \multicolumn{2}{c}{ Specific surface area $\left(\mathrm{m}^{2} / \mathrm{g}\right)$} \\
\cline { 2 - 5 } Testing sample & Natural $\mathrm{pH}$ & $\mathrm{pH}=9$ & Natural $\mathrm{pH}$ & $\mathrm{pH}=9$ \\
\hline $4 \%$ bentonite dispersion & 5.114 & 5.220 & 0.805 & 0.799 \\
$4 \%$ bentonite dispersion $+1 \%(\mathrm{w} / \mathrm{v}) \mathrm{G} 0$ & 31.63 & 33.81 & 0.163 & 0.136 \\
$4 \%$ bentonite dispersion $+1 \%(\mathrm{w} / \mathrm{v}) \mathrm{G} 1$ & 29.31 & 30.51 & 0.169 & 0.152 \\
$4 \%$ bentonite dispersion $+1 \%(\mathrm{w} / \mathrm{v}) \mathrm{G} 2$ & 24.79 & 30.20 & 0.190 & 0.165 \\
$4 \%$ bentonite dispersion $+1 \%(\mathrm{w} / \mathrm{v}) \mathrm{G} 3$ & 26.66 & 31.35 & 0.162 & 0.155 \\
$4 \%$ bentonite dispersion $+1 \%(\mathrm{w} / \mathrm{v}) \mathrm{G} 4$ & 27.98 & 32.42 & 0.165 & 0.145 \\
$4 \%$ bentonite dispersion $+1 \%(\mathrm{w} / \mathrm{v}) \mathrm{G} 5$ & 24.40 & 32.66 & 0.169 & 0.140 \\
$4 \%$ bentonite dispersion $+1 \%(\mathrm{w} / \mathrm{v}) \mathrm{PEA}$ & 11.45 & 25.36 & 0.423 & 0.208 \\
$4 \%$ bentonite dispersion $+1 \%(\mathrm{w} / \mathrm{v}) \mathrm{KCl}$ & 5.812 & 5.311 & 0.781 & 0.796 \\
\hline
\end{tabular}

\subsection{Interaction between PAMAM dendrimers and bentonite}

\subsection{1. $\mathrm{pH}$ value of aqueous solution}

The $\mathrm{pH}$ values as a function of PAMAM dendrimers concentration is presented in Fig. 6 .

Concentration critical point (about $0.5 \mathrm{~g} / \mathrm{L}$ ) can be easily detected in this Figure. The $\mathrm{pH}$ value increased significantly with the increase of concentration below this critical point, while increased smoothly when the concentration is above the point, indicating a $\mathrm{pH}$ buffering effect. 


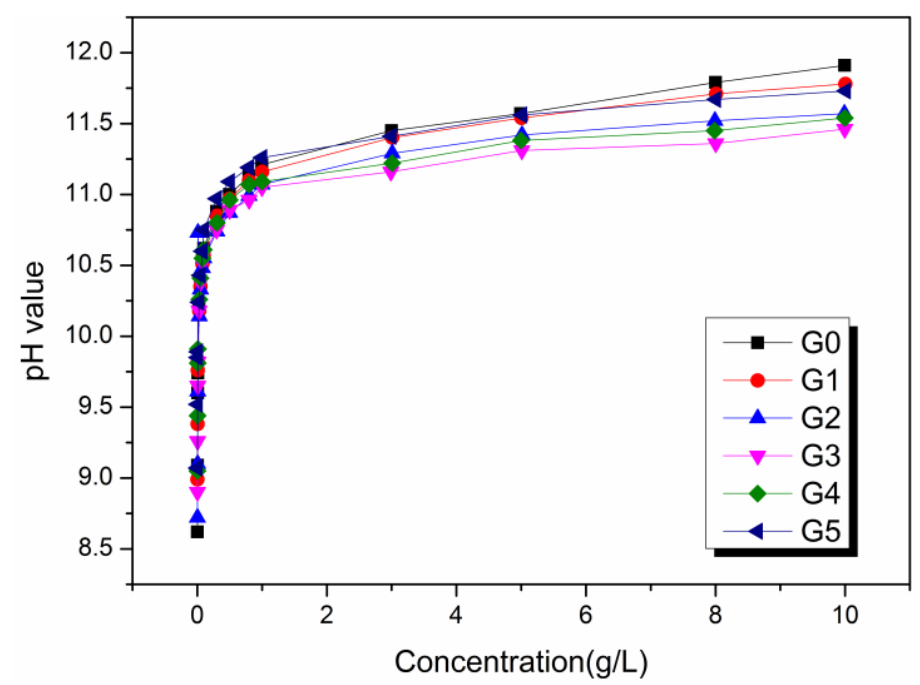

Fig. 6. Variation of $\mathrm{pH}$ values with the increase of PAMAM concentrations.

\subsubsection{Zeta potential}

The zeta potential of montmorillonite particles in aqueous dispersion was measured to investigate the effect of inhibitors on the electrokinetic properties of the clay particles at natural $\mathrm{pH}$ values and $\mathrm{pH}$ value of 9 respectively. Generally, colloidal particles with the zeta potential absolute value greater than $30 \mathrm{mV}$ is considered stable (Garea et al., 2014). Highly negative zeta potential of clay particles have the trend to swell and disperse. As illustrated in Fig. 7(a), the zeta potential of pristine sodium bentonite was about $-39 \mathrm{mV}$, reflecting stable dispersion. The addition of inhibitors decreased the zeta potential of clay particles to different degrees. PAMAM dendrimer from G0 to G5 could decrease the zeta potential from $-39 \mathrm{mV}$ to about $-22.6 \mathrm{mV}$. PEA reduced the zeta potential to a lower value of about $-18.7 \mathrm{mV}$, and $\mathrm{KCl}$ could decrease the zeta potential to about $-11.5 \mathrm{mV}$. According to Mohan and Fogler (1997), reduction of layer charge by $20 \%$ is adequate to prevent swelling of the clay completely. Also Riddick established a stability scale of particles in terms of zeta potential, that zeta potential ranging from $-16 \mathrm{mV}$ to $-30 \mathrm{mV}$ is the threshold of weak dispersion, and zeta potential in the 
range of -10 to $-15 \mathrm{mV}$ indicates the occurrence of particle binding (Ritter and Geraut, 1985). Thus it is can be inferred that the addition of PAMAM dendrimers, PEA and $\mathrm{KCl}$ effectively decrease the zeta potential of clay particles and prevent clay swelling.

Regarding the PAMAM dendrimers, the terminal primary and tertiary amines make the polymers exhibit a weak polyelectrolyte behavior. Their charge density can be tuned by varying the $\mathrm{pH}$ value of the solution. For PAMAM dendrimers, the $\mathrm{pKa}$ of terminal primary amine groups and the tertiary amine groups is between 9-10 and 4-5, respectively (Shi et al., 2005; Garea et al., 2014). For polyether amine, the pKa is estimated to approximate that of 1 , 6-hexanediamine, whose pKa1 and pKa2 values are 9.83 and 10.93, respectively (Wang et al., 2010). According to Horton and Jones (1998), when the $\mathrm{pH}$ value is equal to $\mathrm{pKa}$, the ratio of protonated to non-protonated amine is exactly 1 . For each drop of $1 \mathrm{pH}$ unit, the ratio of protonation to non-protonated amine is increased 10 fold. Hence a decrease of $\mathrm{pH}$ value will improve the protonation degree of amine groups and lead to an increase of charge. As shown in Fig. 7(b), the zeta potential of clay particles became positive for PAMAM dendrimers incorporation when the $\mathrm{pH}$ value was adjusted to about 9, whereas the zeta potentials of the system adding PEA and $\mathrm{KCl}$ were still negative. The zeta potential reverse indicated that special adsorption existed between PAMAM dendrimers and clay particles, which will be characterized in the following part of X-ray diffraction.

When at the natural $\mathrm{pH}$ values, only part of terminal amine groups are protonated, which neutralize the negative sites of clay surface and result in the decrease of zeta potential to some degrees. The decrease of $\mathrm{pH}$ value promotes the protonation of amine groups and lead to the special adsorption of PAMAM dendrimers onto clay surface, thus charge reverse of 
clay particles occurs. While the difference of charge density for PAMAM dendrimers caused the different extent of zeta potential change. G0 is the most effective in decreasing the zeta potential among all generations. PEA always forms a monolayer arrangement in the interlayer of clay whether for dry or wet sample (Zhong et al., 2011). Therefore no charge reverse occurred.

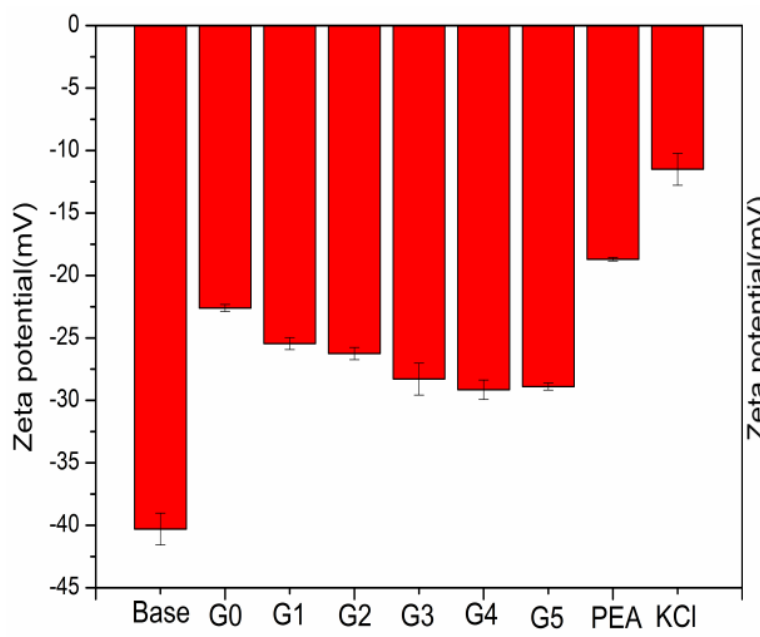

(a)

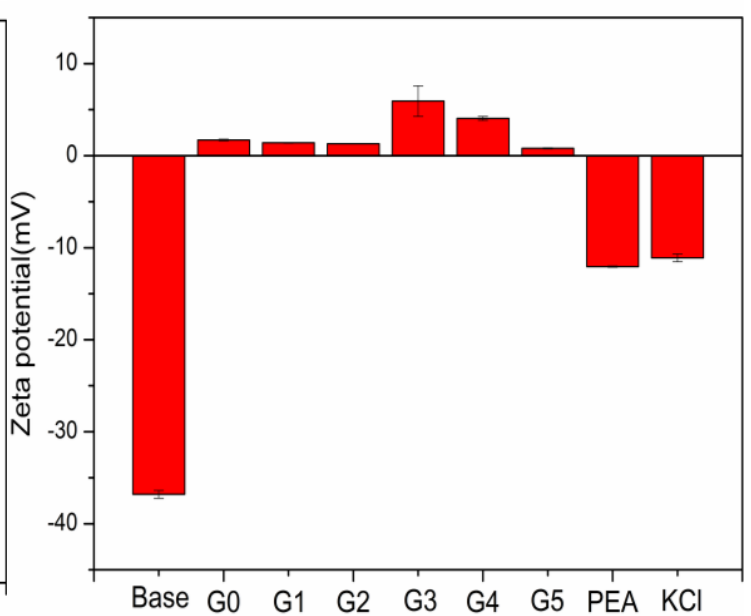

(b)

Fig. 7. Zeta potential measurement of various inhibitor systems at different $\mathrm{pH}$ values. Note:

(a) natural $\mathrm{pH}$ value, (b) $\mathrm{pH}=9$.

\subsubsection{XRD}

Clay swelling is mainly controlled by the component of aqueous solutions with which the clays come into contact (Amorim et al., 2007). The swelling can be directly evaluated by the increase of interlayer spacing. The interlayer spacing of pristine bentonite is $1.23 \mathrm{~nm}$, showing a typical X-ray diffraction pattern of sodium bentonite. After thorough hydration, the interlayer spacing increased as high as $1.95 \mathrm{~nm}$. While the incorporation of PAMAM dendrimers of different generations exhibited different intercalation types. For all the PAMAM dendrimers, when the concentration was low, the interlayer spacing decreased dramatically. For example, when the concentration was $0.35 \mathrm{~g}$, the interlayer spacing 
decreased from $1.95 \mathrm{~nm}$ to $1.38,1.46,1.63,1.52,1.46$ and $1.45 \mathrm{~nm}$ for the dendrimers of different generations respectively. This was the direct evidence of inhibiting clay swelling by PAMAM dendrimers. At low concentrations, PAMAM dendrimers intercalated into the interlayer of clay and exchange the hydrated cationic ions, resulting in the expelling of interlayer water molecules and the decrease of interlayer spacing. While with the increase of concentration, PAMAM dendrimers adopted overlapped orientations in the interlayers, leading to the increase of interlayer spacing.

As shown in Fig. 8(a), when the content of G0 is $0.35 \mathrm{~g}$ and $0.70 \mathrm{~g}$, the related interlayer spacing was $1.38 \mathrm{~nm}$. When the concentration increased as high as $1.75 \mathrm{~g}$, there were two diffraction peaks, indicating mixed phase intercalation existed in the gallery. With the further increase of concentration, only one peak was observed. The value of $1.68 \mathrm{~nm}$ indicated bilayer structure was formed in the interlayer. The same trend was also observed for G2. G2 formed monolayer arrangement, mixed phase, and bilayer structures at lower, intermediate, and higher concentration, respectively. For G1, G3, G4 and G5, it was interesting to find that, monolayer adsorption was observed at low concentration of $0.7 \mathrm{~g}$, and bilayer adsorption was formed at high concentrations, which was different from previous results. According to our former XRD test from dry samples, G0 always formed monolayer structure in the whole range of concentration, G1, G2, G3 and G4 formed monolayer orientation at low concentration, but mixed-phase at higher concentrations. G5 showed limited intercalation because of steric hindrance. This difference can be interpreted as that, the dendrimers assume a changed conformation in the lattice in the process of drying at high temperatures. In addition, the bilayer adsorption explains the charge reverse of clay particles at $\mathrm{pH}$ value of 9 
as discussed above.

The hydrodynamic diameter of dendrimers in solution estimated from molecular models is $1.4,2.2,2.9,3.6,4.5$, and $5.4 \mathrm{~nm}$ for the PAMAM dendrimers from G0 to G5, respectively (Shi et al., 2005). However, the maximum value of interlayer spacing was about $2 \mathrm{~nm}$ for the dendrimer modified bentonite, much less than that of their diameters in aqueous solution (Fig. 9). Lower generation (G0 - G3) PAMAM dendrimers with ethylenediamine core have an ellipsoidal shape, whereas the higher generation (G4 - G5) dendrimers have a roughly spherical shape (Liyanage et al., 2013). This rather small interlayer spacing in comparison with that of polymers indicated that polymers intercalated into the gallery with highly oblate or flattened conformation. This strongly distorted structure can be related to the intrinsic characteristics of PAMAM dendrimers. Electrostatic attraction between protonated terminal amine group and negative clay surface, and hydrogen bonding between amine group and siloxane contribute to the strong interaction between PAMAM dendrimers and clay. Meanwhile, PAMAM dendrimers are very soft and do not preserve their shape in condensed state in the interlayer. Moreover, the absence of macromolecular entanglements in comparison with linear polymers makes PAMAM dendrimers easy to be compressed (Tsukruk et al., 1997), thus explaining the rather small interlayer distance. 


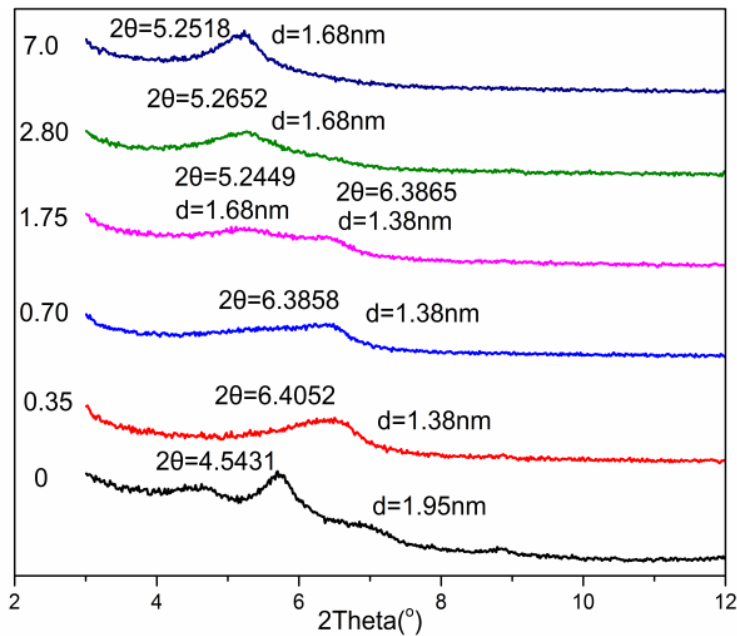

(a)

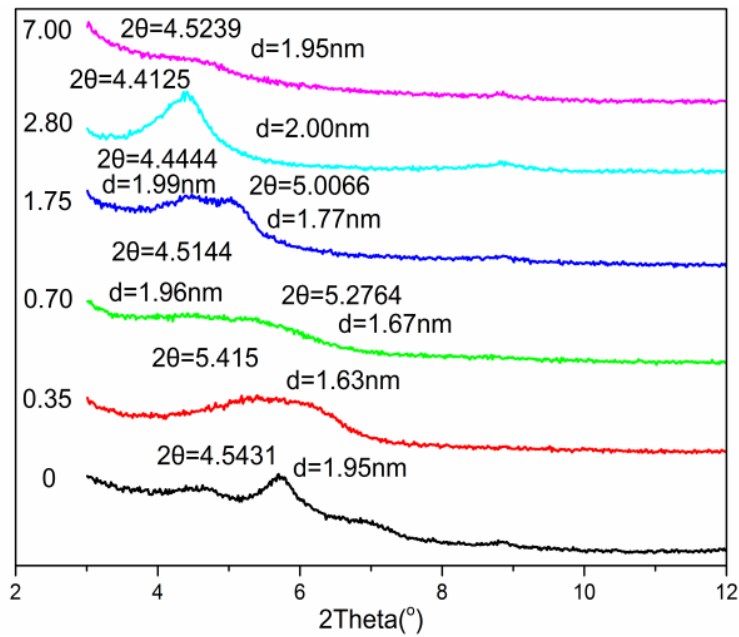

(c)

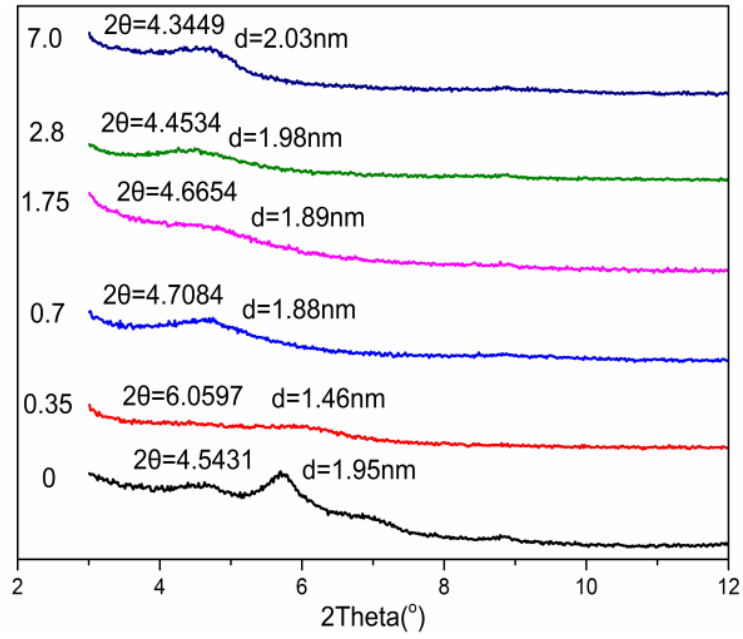

(e)

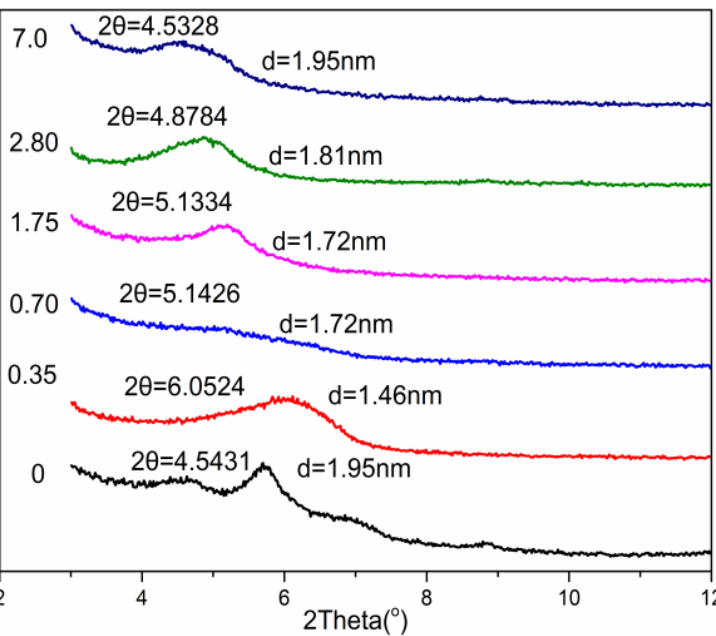

(b)

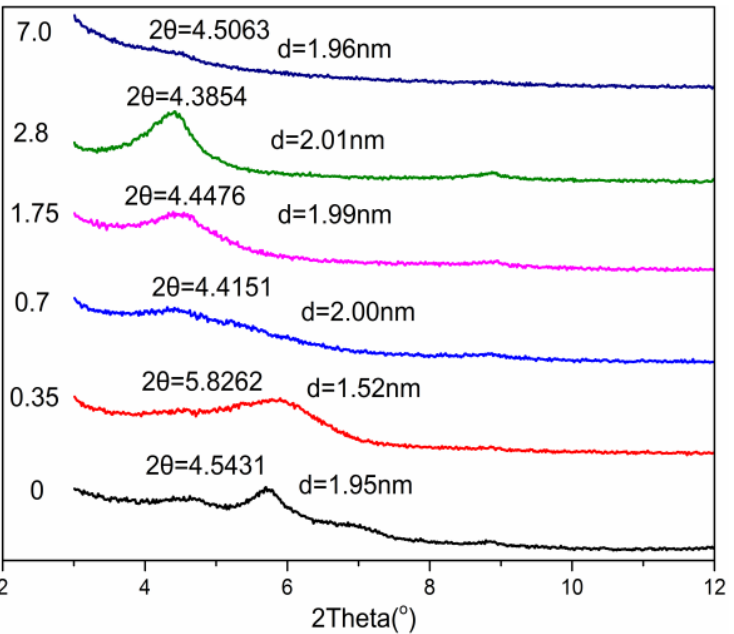

(d)

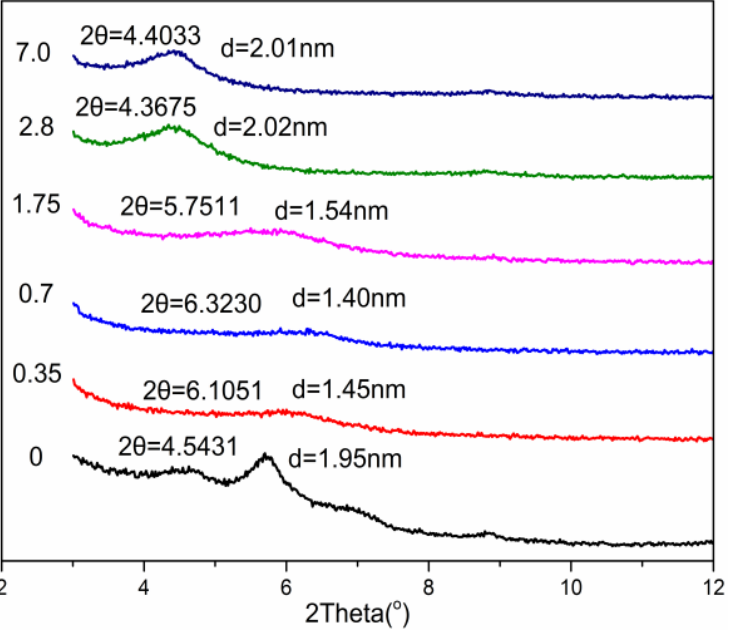

(f)

Fig. 8. X-ray diffraction patterns of PAMAM dendrimers modified bentonite with different

concentrations with wet samples. (a) G0; (b) G1; (c) G2; (d) G3; (e) G4; (f) G5. 


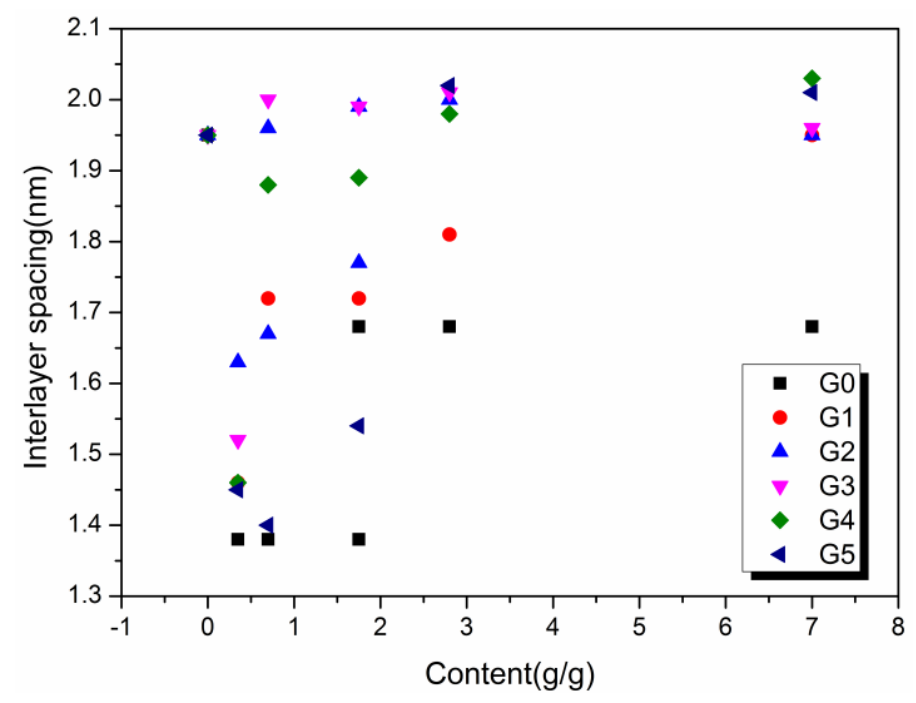

Fig. 9. Variation of interlayer spacing with concentration of PAMAM dendrimers for wet samples.

Table 2 and Table 3 illustrate the interlayer spacing of PAMAM dendrimers modified bentonite at content of $2.8 \mathrm{~g}$ under different $\mathrm{pH}$ values. There was no apparent change of interlayer spacing for G0, G1, G2, G3 and G4 with dry sample, whereas for G5, the interlayer spacing was $1.36 \mathrm{~nm}$ at natural $\mathrm{pH}$ value, while a more expanded phase $(1.88 \mathrm{~nm})$ was observed when the $\mathrm{pH}$ value was adjusted to 9.0. The decrease of $\mathrm{pH}$ value improved the protonation of peripheral primary amine groups, which facilitate the intercalation. From table 3 , it was obviously noted that the interlayer spacing was lower at $\mathrm{pH}$ value of 9.0 than that of natural $\mathrm{pH}$ conditions. This could also be correlated to, that the decrease of $\mathrm{pH}$ value enhances the protonation of terminated amine groups, which can be anchored on the adjacent layers with multi-adsorption and bond the sheets tighter, generating a lower interlayer spacing. A similar phenomenon was also reported by Chou et al. (2004). Furthermore, a conclusion could be drawn that, reducing $\mathrm{pH}$ value of the aqueous solution leads to improved inhibitive capacity of PAMAM dendrimers. 
Table 2 Interlayer spacing of PAMAM dendrimer modified bentonite at different $\mathrm{pH}$ values with dry sample $(2.8 \mathrm{~g})$.

\begin{tabular}{|c|c|c|c|c|}
\hline \multirow[b]{2}{*}{ Sample } & \multicolumn{2}{|c|}{ Natural pH } & \multicolumn{2}{|c|}{$\mathrm{pH}=9.0$} \\
\hline & $2 \operatorname{Theta}\left({ }^{\circ}\right)$ & $\begin{array}{c}\text { Interlayer spacing } \\
(\mathrm{nm})\end{array}$ & $2 \operatorname{Theta}\left({ }^{\circ}\right)$ & $\begin{array}{c}\text { Interlayer spacing } \\
(\mathrm{nm})\end{array}$ \\
\hline G0 & 6.6298 & 1.33 & 6.4500 & 1.37 \\
\hline G1 & 6.5882 & 1.34 & 6.4690 & 1.37 \\
\hline \multirow{2}{*}{ G2 } & 4.9134 & 1.80 & 4.9804 & 1.77 \\
\hline & 6.4676 & 1.37 & 6.4385 & 1.37 \\
\hline \multirow{2}{*}{ G3 } & 4.9141 & 1.80 & 4.8923 & 1.81 \\
\hline & 6.5051 & 1.36 & 6.3234 & 1.40 \\
\hline \multirow{2}{*}{ G4 } & 5.0605 & 1.75 & - & - \\
\hline & 6.5412 & 1.35 & 6.4002 & 1.38 \\
\hline \multirow{2}{*}{ G5 } & - & - & 4.7105 & 1.88 \\
\hline & 6.4880 & 1.36 & 6.3481 & 1.39 \\
\hline
\end{tabular}

Table 3 Interlayer spacing of PAMAM dendrimer modified bentonite at different $\mathrm{pH}$ values with wet sample $(2.8 \mathrm{~g})$.

\begin{tabular}{ccccc}
\hline & \multicolumn{2}{c}{ Natural $\mathrm{pH}$} & \multicolumn{2}{c}{$\mathrm{pH}=9.0$} \\
\cline { 2 - 5 } Sample & $2 \operatorname{Theta}\left({ }^{\circ}\right)$ & $\begin{array}{c}\text { Interlayer spacing } \\
(\mathrm{nm})\end{array}$ & $2 \mathrm{Theta}\left({ }^{\circ}\right)$ & $\begin{array}{c}\text { Interlayer spacing } \\
(\mathrm{nm})\end{array}$ \\
\hline $\mathrm{G} 0$ & 5.2652 & 1.68 & 6.1979 & 1.43 \\
$\mathrm{G} 1$ & 4.8784 & 1.81 & 5.1527 & 1.72 \\
$\mathrm{G} 2$ & 4.4125 & 2.00 & 5.0236 & 1.77 \\
$\mathrm{G} 3$ & 4.3854 & 2.01 & 4.5832 & 1.93 \\
$\mathrm{G} 4$ & 4.4534 & 1.98 & 4.5870 & 1.93 \\
$\mathrm{G} 5$ & 4.3675 & 2.02 & 5.5327 & 1.60 \\
\hline
\end{tabular}

\subsection{Inhibitive mechanism analysis}

A possible model illustrating the interaction between PAMAM dendrimers and clay is presented in Fig. 10. At lower concentration, PAMAM dendrimers intercalated into the clay lattice with monolayer arrangement, whereas at higher concentration bilayer orientation was formed. The multi-adsorption between terminal amine groups and negative sites of clay 
surface could bind the adjacent lattices together, expelling out the interlayer water molecules, corresponding to an effective inhibitive performance, as confirmed by the former inhibitive evaluation results. A proper decrease of $\mathrm{pH}$ value prompted the degree of protonation, which intensified the interaction between PAMAM dendrimers and clay, and lead to the further reduction of interlayer spacing, namely reflecting to the improvement of inhibition. The charge density played a vital role of inhibitive performance. For G0, whose charge density was higher than that of other generations, exhibited superior performance to other generations.

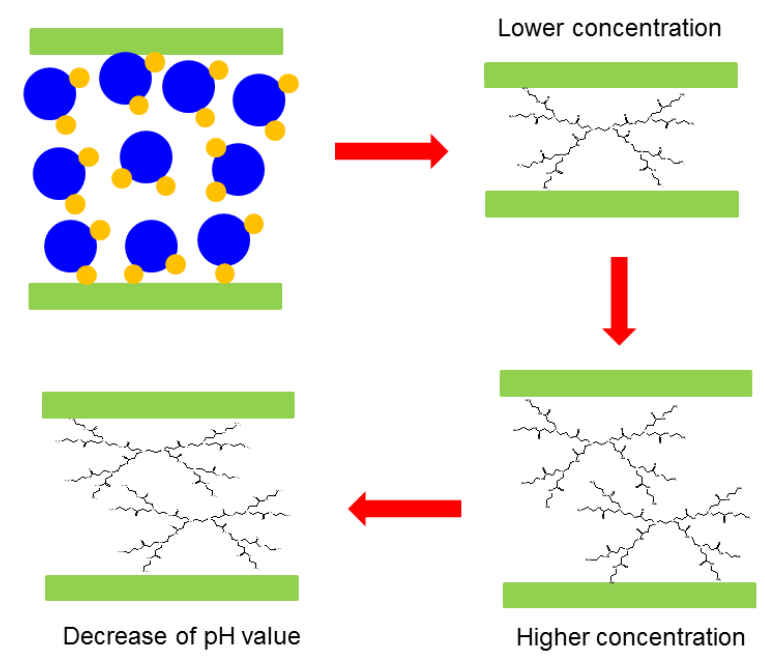

Fig. 10. The interaction between PAMAM dendrimers and bentonite.

\section{Conclusions}

The inhibitive properties of PAMAM dendrimers were further studied in this paper. PAMAM dendrimers ranging from G0 to G5 exhibited effective performance in inhibiting shale hydration and dispersion. G0 and G5 were superior to PEA, while G1, G2, G3 and G4 performed better than $\mathrm{KCl}$. For the candidate PAMAM dendrimers, when intercalated into the clay interlayer in aqueous solution, monolayer arrangement is formed at lower concentration, 
and bilayer orientation is formed at higher concentration. The multi-terminal amine groups can effectively bind the adjacent layers together with electrostatic attraction and hydrogen bonding, which expels the water molecules out of the interlayer and contributes to the suppression of clay dispersion. The inhibitive performance of PAMAM dendrimers is associated with $\mathrm{pH}$ value of aqueous medium. Reducing the $\mathrm{pH}$ value of aqueous solution intensifies the interaction between the polymers and clay, and induces the decrease of hydrated interlayer spacing when the dendrimers were intercalated into the galleries, corresponding to an enhancement of the inhibitive properties of PAMAM dendrimers. Understanding the $\mathrm{pH}$ dependence of PAMAM dendrimer inhibitive properties is of vital importance for field application. PAMAM dendrimers can be considered as potential candidates for inhibiting shale hydration and dispersion.

\section{Acknowledgements}

This work was financially supported by National Science Foundation of China (No. 51374233, No. 51474236), China Postdoctoral Science Foundation (No. 2014M551986) and the Postdoctoral Innovative Project Foundation of Shandong Province (No. 201303060).

\section{References}

Abdel Rehim, M.H., Youssef, A.M., Essawy, H.A., 2010. Hybridization of kaolinite by consecutive intercalation Preparation and characterization of hyperbranched poly(amidoamine)-kaolinite nanocomposites[J]. Mater. Chem. Phys. 119, 546-552.

Al-Arfaj, M. K., Amanullah, M., Sultan, A.S., Hossain, M. E., Abdulraheem, A., 2014. Chemical and mechanical aspects of wellbore stability in shale formations: a literature review. SPE 171682, Abu Dhabi International Petroleum Exhibition and Conference, Abu 
Dhabi, 10-13 November.

Amanullah, M., Aramco, S., 2013. Dendrimers and dendritic polymers-application for superior and intelligent fluid development for oil and gas field applications. SPE 164162, SPE Middle East Oil and Gas Show and Conference, Manama, Bahrain, 10-13 March.

Amorim, C.L.G., Lopes, R.T., Barroso, R.C., Queiroz, J.C., Alves, D.B., Perez, C.A., Schelin, H.R., 2007. Effect of clay-water interactions on clay swelling by X-ray diffraction[J]. Nucl. Instrum. Meth. A. 1,768-770.

Chou, C.C., Chang, Y.C., Chiang, M.L., Lin, J.J., 2004. Conformational change of trifunctional poly(oxypropylene) amines intercalated within a layered silicate confinement. Macromolecules 37, 473-477.

Donham, F., Young, S., 2009. High performance water based drilling fluids design. Offshore Mediterranean Conference and Exhibition, Ravenna, 25-27 March.

Galindo, K.A., Zha, W., Zhou, H., Deville, J.P., 2015. Clay-free high performance water-based drilling fluid for extreme high temperature wells. SPE/IADC 173017, SPE/IADC Drilling Conference and Exhibition, London, 17-19 March.

Garea, S.A., Ghebaur, A., Vasile, E., 2014. Hybrid materials based on dendritic polymer and halloysite[J]. Mater. Plast. 51(1), 12-16.

Gillies, E.R. and Frechet, J.M.J., 2005. Dendrimers and dendritic polymers in drug delivery[J]. Drug Discov. Today 10(1), 35-43.

He, W., Gomez, S.L., Leonard, R.S., Li, D.T., 2014. Shale-fluid interactions and drilling fluid designs. IPTC 17235, International Petroleum Technology Conference, Doha, 20-22 January. Horton, D., Jones, A., 1998. Clay stabilizing agent and a method of use in subterranean 
formations to inhibit clay swelling. US 5771971.

Kaiser, A., 2013. Environmentally friendly emulsion breakers: vision or reality? SPE 164073, SPE International Symposium on Oilfield Chemistry, The Woodlands, 8-10 April.

Lai, N., Qin, X., Ye, Z., Peng, Q., Zhang, Y., Ming, Z., 2013. Synthesis and evaluation of a water-soluble hyperbranched polymer as enhanced oil recovery chemical[J]. J. Chem. 1-11. Li, L., Ma, C., Yuan, X., Fan, J., Yang, Y., Li, Y., 2012. Synthesis and application of dendrimers in oilfield chemistry[J]. Modern Chemical Industry 32(6), 16-21. (in Chinese)

Liu, S., Mo, X., Zhang, C., et al., 2004. Swelling inhibition by polyglycols in montmorillonite dispersions[J]. J. Disper. Sci. Technol. 25(1), 63-66.

Liyanage, A.U., Ikhuoria, E.U., Adenuga, A.A., Remcho, V.T., Lerner, M.M., 2013. Synthesis and characterization of low-generation polyamidoamine (PAMAM) dendrimer-sodium montmorillonite (Na-MMT) clay nanocomposites[J]. Inorg. Chem. 52, 4603-4610.

Miller, R.F., 2011. Shale hydration inhibition agents and method of use. US 8026198.

Mohan, K.K. and Fogler, H. S., 1997. Effect of pH and layer charge on formation damage in porous media containing swelling clays[J]. Langmuir 13, 2863-2872.

Mo, Z., Niu, G., Chen, H., Wu, Y., 2008. Synthesis and characterization of hyperbranched poly(amine-ester)/lanthanum/montmorillonite nanocomposites[J]. Mater. Let. 62, 1743-1746.

Patel, A., Gomez, S.L., 2013. Shale inhibition: what works? SPE 164108, SPE International Symposium on Oilfield Chemistry, The Woodlands, 8-10 April.

Patel, A., Stamatakis, E., Young, S., Cliffe, S., 2002. Designing for the future- a review of the design, development and testing of a novel, inhibitive water-based drilling fluid. AADE-02-DFWM-HO-33, AADE 2002 Technical Conference, Texas, 2-3 April. 
Patel, A., Stamatakis, E., Young, S., Friedheim, J., 2007. Advances in inhibitive water-based drilling fluids- can they replace oil-based muds? SPE 106476, SPE International Symposium on Oilfield Chemistry, Houston, 28 February- 2 March.

Reid, P.I., Dolan, B., Cliffe, S., 1995. Mechanism of shale inhibition by polyols in water based drilling fluids. SPE 28960, SPE International Symposium on Oilfield Chemistry, San Antonio, 14-17 February.

Ritter, A.J. and Geraut, R., 1985. New optimization drilling fluid programs for reactive shale formations. SPE 14247, $60^{\text {th }}$ Annual Technical Conference and Exhibition of the Society of Petroleum Engineers, Las Vegas, 22-25 September.

Rivers, G.T., Tian, J., Trenery, J.B., 2011. Kinetic gas hydrate inhibitors in completion fluids. US 8048827.

Shi, X., Bányai, I., Lesniak, W.G., Islam, M.T., Országh, I., Balogh, P., Baker, J.R., Balogh, L.P., 2005. Capillary electrophoresis of polycationic poly(amidoamine) dendrimers[J]. Electrophoresis 26, 2949-4959.

Stamatakis, E., Thaemlitz, C.J., Coffin, G., Reid, W., 1995. A new generation of shale inhibitors for water-based muds. SPE/IADC 29406, SPE/IADC Drilling Conference, Amsterdam, 28 February-2 March.

Stanciu, C., Vo, L.K., Nguyen, P.D., Weacer, J.D., 2015. Maintaining well productivity through controlling fines migration and scale formation. SPE 174364, EUROPEC, Madrid, 1-4 June.

Stelger, R.P. and Leung, P.K., 1998. Quantitative determination of the mechanical properties of shales. SPE 18024. SPE Annual Technical Conference and Exhibition, Houston, 2-5 
October.

Suter, J.L., Coveney, P.V., Anderson, R.L., Greenwell, H.C., Cliffe, S., 2011. Rule based design of clay-swelling inhibitors[J]. Energ. Environ. Sci. 4, 4572-4586.

Teixeira, G.T., Lomba, R.F.T., Francisco, A.D.S., Silva, J.F.C.D., Nascimento, R.S.V., 2014. Hyperbranched polyglycerols, obtained from environmentally benign monomer, as reactive clays inhibitors for water-based drilling fluids[J]. J. Appl. Polym. Sci. 131(12), 2-7.

Tomalia, D.A, Baker, H., Dewald, J., Hall, M., Kallos, G., Martin, S., Roeck, J., Ryder, J., Smith, P., 1985. A new class of polymers: starburst- dendritic macromolecules[J]. Polym. J. 17(1), 117-132.

Tsukruk, V.V., Rinderspacher, F., Bliznyuk, V.N., 1997. Self-assembled multilayer films from dendrimers[J]. Langmuir 13(8), 2171-2176.

Van Oort, E., Hale, A.H., Mody, F.K., Roy, S., 1994. Transport in shales and the design of improved water-based shale drilling fluids. SPE 28309, SPE Annual Technical Conference and Exhibition, New Orleans, 25-28 September.

Van Oort, E., 1997. Physico-chemical stabilization of shales. SPE 37263, SPE International Symposium on Oilfield Chemistry, Houston, Texas, 18-21 February.

Van Oort, E., 2003. On the physical and chemical stability of shales[J]. J. Petrol. Sci. Eng. 38, 213-235.

Wang, J., Liu, G., Wang, L., Li, C., Xu, J., Sun, D., 2010. Synergistic stabilization of emulsions by poly(oxypropylene)diamine and laponite particles[J]. Colloid. Surface. A. 353, $117-124$

Xuan, Y., Jiang, G., Li, Y., Wang, J., Geng, H., 2013. Inhibiting effect of dopamine adsorption 
and polymerization on hydrated swelling of montmorillonite[J]. Colloid. Surface. A. 422, $50-60$.

Young, S. and Ramses, G., 2006. Drilling Performance and Environmental Compliance Resolution of Both with a Unique Water Based Fluid. SPE/IADC 103967, SPE/IADC Indian Drilling Techology Conference and Exhibition, Mumbai, 16-18 October.

Zhang, L.M., Tan, Y.B., Li, Z.M., 2001. New water-soluble ampholytic polysaccharides for oilfield drilling treatment: a preliminary study[J]. Carbohyd. Polym. 44(3), 255-260.

Zhang, L., Wang, X., Hu, X., Zhang, B., Wang, Z., 2015. Ultra-high temperature water base drilling fluid[J]. Drilling fluid \& Completion Fluid 32(4), 5-8. (in Chinese)

Zhong, H., Qiu, Z., Huang, W., Cao, J., 2011. Shale inhibitive properties of polyether diamine in water-based drilling fluid[J]. J. Petrol. Sci. Eng. 78, 510-515.

Zhong, H., Qiu, Z., Huang, W., Sun, D., Zhang, D., Cao, J., 2015. Synergistic stabilization of shale by a mixture of polyamidoamine dendrimers modified bentonite with various generations in water-based drilling fluid[J]. Appl. Clay Sci. 114, 359-369. 